\title{
Design Processes for User Engagement with Mobile Health: A Systematic Review
}

\author{
Tochukwu Ikwunne, Lucy Hederman, P. J. Wall \\ ADAPT Centre, Trinity College Dublin, Ireland
}

\begin{abstract}
Despite the importance of user engagement in mHealth system efficacy, many such interventions fail to engage their users effectively. This paper provides a systematic review of 10 years of research (32 articles) on mHealth design interventions conducted between 2011 and 2020. The PRISMA (Preferred Reporting Items for Systematic Reviews and MetaAnalyses) model was used for this review with the IEEE, Medline EBSCO Host, ACM, and Springer databases searched for English language papers with the published range. The goal of this review was to find out which design process improves user engagement with mHealth in order to guide the development of future mHealth interventions. We discovered that the following six analytical themes influence user engagement: design goal, design target population, design method, design approach, sociotechnical aspects, and design evaluation. These six analytical themes, as well as 16 other specific implementations derived from the reviewed articles, were included in a checklist designed to make designing, developing, and implementing mHealth systems easier. This study closes a gap in the literature by identifying a lack of consideration of socio-cultural contexts in the design of mHealth interventions and recommends that such socio-cultural contexts be considered and addressed in a systematic manner by identifying a design process for engaging users in mHealth interventions. Based on this, our systematic literature review recommends that a framework that captures the socio-cultural context of any mHealth implementation be refined or developed to support user engagement for mHealth.
\end{abstract}

Keywords-Design process; mobile health; socio-cultural; usercentered design; user engagement

\section{INTRODUCTION}

Many mHealth interventions fail to achieve or sustain their stated goals [1][2]. Many reasons have been put forward to explain this, one of which asserts that the effectiveness of mHealth initiatives is overly dependent on user engagement [3][4][5]. In this context, the concept of user engagement is critical. Although the term "user engagement" has several different interpretations, it is critical to have a common meaning of the term's specific definition because the various interpretations have led to a great deal of misunderstanding [6]. For the purposes of this study, user engagement should be defined as "the emotional, cognitive, and behavioral connection that exists between a user and a resource at any point in time and possibly over time" [7]. User engagement is critical in mHealth, with many researchers (e.g., [8][9]) arguing that the mHealth design process should take into account the needs of various users. However, many current mHealth interventions are based on pre-existing healthcare system constructs [10], encouraging designers to base their

This research was conducted with the financial support of Science Foundation Ireland under Grant Agreement No. grant 18/CRT/6222 at the ADAPT SFI Research Centre at Trinity College Dublin. designs on assumptions that have not been validated with primary user input [11]. As a result, the interventions that result are less effective than those that include end-user needs [10] and input from relevant stakeholders such as commercial app industries and design experts [9]. The author in [11] defines user-centered design as a method that is informed by the needs and understanding of a particular end-user group and plays an important role in achieving user engagement with technology. People must engage in mHealth interventions for them to be effective, but engagement is frequently inadequate [12].

It has been stated that the effectiveness of mHealth initiatives is highly depended on user engagement [3]. However, despite the claimed importance of user engagement in mHealth system efficacy, many such interventions frequently lack user-engaging attributes [13]. According to [13], some mHealth apps lacked engaging and customizable features because the apps did not include any specific strategies to facilitate user engagement. Furthermore, [14] indicates that user engagement is a critical factor in determining the success of any mobile application.

Thus, additional research is warranted to improve understanding of user engaging features in technology in general, and mHealth, as well as to develop techniques and methodologies to facilitate and sustain user engagement [15]. As discussed in [11], it is also important to consider the sociocultural contexts associated with user engagement when attempting to achieve user engagement with technology. According to [16], a lack of engagement with mHealth systems is caused by socio-cultural and organizational issues, such as when mHealth applications developed in the Global North are implemented in the Global South, where there may be numerous social, cultural, and belief differences. In such cases, it is critical that implementation take users' sociocultural contexts into account in order to improve mHealth systems. This point is emphasized further by [17], who claims that the assumption that technology developed in the Global North can simply be dropped into the Global South and expected to work is a "fallacy."

This systematic review identifies a gap in the literature by highlighting the lack of consideration of users' socio-cultural contexts in the design of mHealth interventions and proposes that such user group socio-cultural contexts be considered. This is because techno-centric approaches to mHealth design and user engagement that are solely focused on technology, as well as other approaches that rely on existing universal frameworks for user-centered design, have been shown to be ineffective [18]. 
In this systematic review, we seek to present the process of designing engaging mHealth interventions, situating the design process within the context of a user-centered design framework, and contextualizing the results by also incorporating the design processes of other mHealth interventions. As their guiding approaches, these are explicitly named design approaches user-centered, human-centered design, double diamond, and Hasso-Plattner Institute. As a result, the paper emphasizes the importance of improving understanding of user-engaging features in technology in broad sense, and mHealth precisely, as well as the need of developing more robust techniques and methodologies to facilitate and sustain user engagement.

\section{LITERATURE REVIEW}

This review of the literature begins with a discussion of the body of work dealing with the success and failure of mHealth. The section then examines the body of work on designing mHealth for engaging experiences before emphasizing the importance of considering the fit between various conceptions of engagement and the design process in mHealth design.

\section{A. Design Success and Failure in mHealth}

In the field of mHealth, defining success or failure is a difficult task. What is clear is that implementing such systems in a sustainable and scalable manner is difficult. The author in [1] states that "most information systems in developing countries fail either completely or partially," while [19] states that "successful examples of computerisation can be found... but frustrating stories of systems that failed to fulfill their initial promise are more common" (p.1). The success of any new technology is dependent on its successful integration, diffusion, and long-term use by intended users, according to [20]. Projects have been shown to be productive when they are tailored to the local context and language [21], and when they are developed and implemented with the participation of local private service providers [21][22]. A number of studies have demonstrated that mHealth interventions in the Global South are useful, particularly in improving treatment adherence, appointment compliance, data collection, and the development of support networks for health workers [23][24][25]. Although it is acknowledged that mHealth, particularly in the Global South, has great potential, many mHealth systems have historically failed to deliver on their initial promises [19]. There are numerous challenges and risks associated with the design, implementation, and adoption of such systems [26][27].

There have been numerous explanations advanced for this high level of mHealth failure. One of the primary causes of the failure was identified in [28]. Socio-cultural considerations, according to the article, have a significant impact on the implementation of any health information system. They discussed about the socio-cultural issues that arise when health information systems are transferred between two African developing countries' public health sectors (Mozambique and South Africa). The article demonstrates that transferring between two countries involves issues such as cultural differences, adjustment, and adaptation. While the transfer was deemed successful, the health information system needed to be flexible enough to support local variations. Similarly, a number of articles [29][30][31][32] have argued that successful implementations necessitate a better understanding of user groups' sociocultural contexts due to their importance and impact on the scale and sustainability of mHealth initiatives.

A major cause of failure, according to [33], is an unsuitable design in relation to the needs and context of use. Similarly, taking a techno-centric approach to mHealth implementation without considering socio-technical issues, according to [34], can be detrimental. Another reason for mHealth failure is the use of a top-down approach by implementers [35]. This approach is techno-centric, with users having no control over the technology that they expect to use. Furthermore, many mHealth systems are designed, developed, and imported from the Global North. According to [17], assuming that such systems will fit into any Global South country without considering users is a "fallacy." This highlights the significance of creating engaging experiences for users of mHealth interventions.

\section{B. Designing for Engaging mHealth Experience}

Although designing for engaging experiences is a widely stated goal of interactive system development across many disciplines, there are no guidelines in place to communicate designers' efforts to make things engaging [36]. The problem has been exacerbated by the lack of a unified definition of engagement. It is difficult to know whether the systems we design are engaging or to identify which aspects of technology interaction engage or fail to engage users if user engagement is not understood [37]. There are several definitions of user engagement, and the various viewpoints have resulted in a great deal of misunderstanding [6]. It's unclear how valuable these viewpoints are to designers. [38]. The author in [6] defined user engagement as "the total set of user relationships toward IS and their development, implementation, and use" (p. 514). The psychological state of mind required by the user to enjoy the representation, i.e., a willing suspension of disbelief, has also been defined as "user engagement" [39]. Other points of view on user engagement have shifted the focus away from the individual user and toward the designer. The author in [40] investigated methods for attracting people and encouraging interaction. The author in [41] was interested in motivating and improving the user experience of the application, whereas [42] defined engagement relying on their synthesizing of esthetical, flows, enjoy, and information interaction theories, as well as previous work in the application areas of video games, web searching, and educational software. Other definitions include [43] user experience, spatiotemporal, compositional, and sensual "threads of experience."

An important but frequently overlooked aspect of engagement research is the fit between various conceptions of engagement and the design process. The evaluation of user engagement is critical in the design of engaging experiences. However, there is very little attention given to incorporating engagement measures into the design process [38], implying that an improved mHealth design process is required to strengthen user engagement [44]. 


\section{MATERIAL AND METHODS}

The literature review provides a comprehensive description of the current state of the mHealth design process from the standpoint of user engagement. As a result, it can be used to inform future research and studies in the mHealth design process as a means of improving user engagement with mHealth technologies.

\section{A. Introduction}

A systematic qualitative analysis was used to categorize data based on different analytical themes. Articles from 2011 to 2020 were searched in four electronic databases (IEEE, Medline EBSCO Host, ACM, and Springer Link). The time period 2011 to 2020 was chosen to ensure that relevant articles associated with existing design process frameworks to improve user engagement with mHealth technology were found. The search string and their combinations that were used include "design process OR design process framework", "design process evaluations AND mobile health", "mobile health OR mHealth", "user engagement AND mHealth design process", "user engagement AND health", "mHealth AND interventions", "mHealth AND design process", "mHealth applications AND user engagement". This ensures that the mHealth design process is covered broadly across disciplines such as health informatics, information technology, and human-computer interaction (HCI). The search and selection process are depicted in Fig. 1. According to Fig. 1, the search yielded 3700 articles, 3100 of which remained after duplicates were removed. Another 2496 articles were eliminated because they were either (1) not published in English, (2) lacked full text, or (3) did not discuss the design process of mHealth interventions. This step resulted in 604 distinct articles. A further 572 articles were eliminated based on the following criteria: types of interventions studied - articles that do not deal with health interventions are excluded; if they did not report measured outcomes such as performance-based measures, self-report measures, or clinician-reported measures; and if they were not peer-reviewed.

This leaves 32 articles for review. The majority of the 32 articles included in the review came from Medline, with 20 articles, Springer and ACM each having 5 articles, and IEEE having the fewest, with only two. These articles were examined using the set of analytical themes described in the following section.

\section{B. Thematic Analysis and Coding Scheme}

The analysis of 32 selected articles is guided by [45] "six model of thematic analysis." Table I shows the themes used to categorize reviewed articles. According to [45], thematic analysis "provides a flexible and useful tool that can potentially provide a rich and detailed, yet complex account of data."

The following themes were generated in total: design process goal, design approach, whether socio-technical aspects of intervention were addressed, design methods, design target audience, scalability, and design validation and evaluation.

The six themes are generated in accordance with the [45] model.

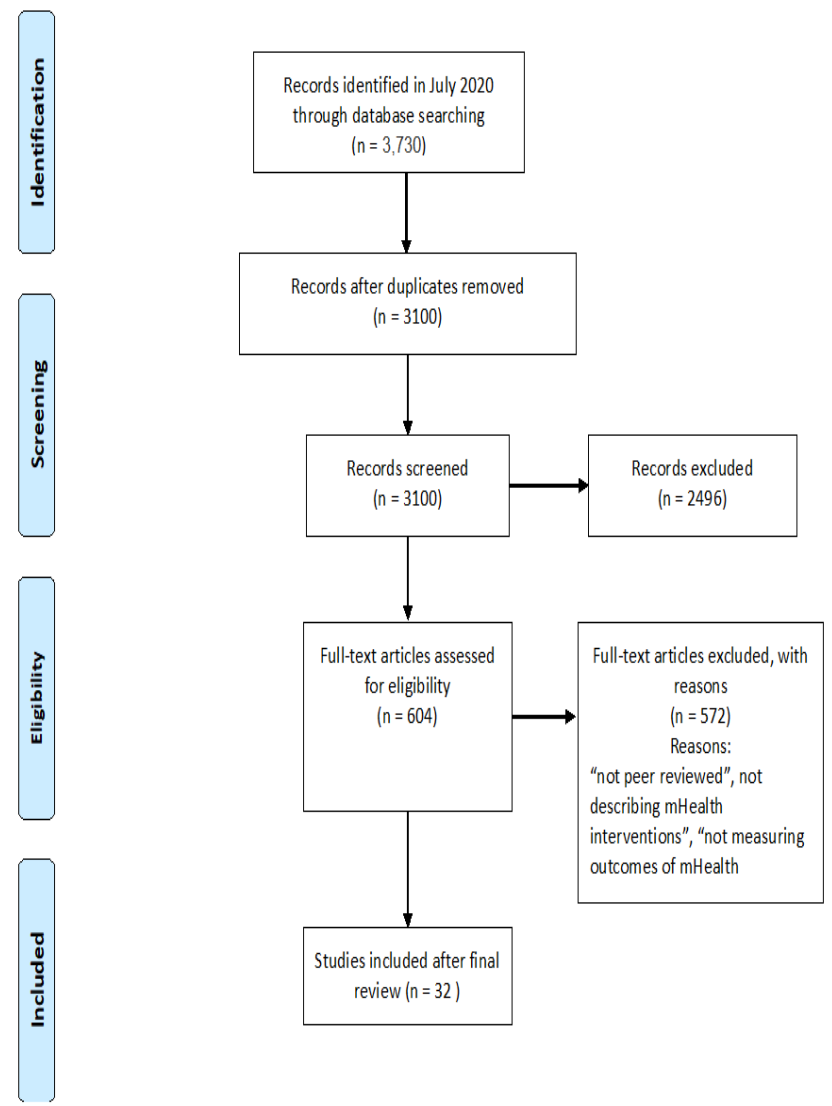

Fig. 1. The Article Selection Workflow.

In order to improve user engagement with mHealth interventions, the first step was to conduct a thorough review of the selected articles, address and analyze the articles, and keep in mind how the selected articles described the mHealth design process. The second step was to generate preliminary codes by highlighting phrases or sentences in the selected articles and creating shorthand labels (codes) to describe their content. Coding is the process of breaking down large amounts of data into smaller chunks of meaning. The codes were created and modified during the coding process without the use of pre-set codes. The coding was completed on an Excel sheet with the intention of not coding the entire data set because the primary concern is to address and analyze the data associating design process of improving user engagement. Two people coded the articles independently. Before moving on to the rest of the articles, each of the codes was compared, discussed, and modified in the third step. Despite the fact that not all of the text was coded, every coded reviewed article was relevant to or specifically addressed user engagement improvement. The fourth step was to look through the codes for a theme, idea, or concept that captured and summarized the data's meaningful and recurring patterns. According to [45], there are no strict guidelines about what constitutes a theme. A theme's significance defines it. The codes were scrutinized at this point to ensure that they fit together into a larger theme that addresses the design process of improving user engagement. The fifth, sixth, and final steps involved naming, reviewing, and refining codes to create the six themes. 
TABLE I. THEMES USED TO CATEGORIZE REVIEWED ARTICLES

\begin{tabular}{|c|c|c|}
\hline Themes & Definitions & Supporting Review Articles \\
\hline $\begin{array}{l}\text { Goal of the } \\
\text { design }\end{array}$ & $\begin{array}{l}\text { The theme design } \\
\text { goals are the purposes } \\
\text { for design work that } \\
\text { are typically agreed } \\
\text { upon by designers of } \\
\text { such design work. }\end{array}$ & $\begin{array}{l}\text { "The primary analysis is } \\
\text { concerned with the marginal effect } \\
\text { that is the average over time, of } \\
\text { the contrast between the two } \\
\text { possible intervention options. In } \\
\text { secondary analysis, moderation } \\
\text { with the goal of understanding in } \\
\text { which circumstances one } \\
\text { intervention option is more effect, } \\
\text { can be explored". (Review 31) }\end{array}$ \\
\hline $\begin{array}{l}\text { Design target } \\
\text { populations }\end{array}$ & $\begin{array}{l}\text { Design target } \\
\text { populations are users } \\
\text { who mHealth } \\
\text { designers consider } \\
\text { when developing } \\
\text { mHealth interventions. }\end{array}$ & $\begin{array}{l}\text { "The study showed, however, that } \\
\text { patients were satisfied with the } \\
\text { phone application and it improved } \\
\text { on their self-reported depressive } \\
\text { symptoms" } \\
\text { (Review 6) }\end{array}$ \\
\hline $\begin{array}{l}\text { Design } \\
\text { methods }\end{array}$ & $\begin{array}{l}\text { Design methods are } \\
\text { techniques or tools for } \\
\text { design work that } \\
\text { provide a variety of } \\
\text { activities that a } \\
\text { designer may use as } \\
\text { part of the overall } \\
\text { design process. }\end{array}$ & $\begin{array}{l}\text { We identified variables that } \\
\text { corresponded to patient and } \\
\text { scientific research priorities, } \\
\text { discussed potential measurement } \\
\text { schemes, and began to investigate } \\
\text { technological options (eg, data } \\
\text { streams, sensors, active tasks, } \\
\text { analytical methods). We also } \\
\text { started talking about a variety of } \\
\text { technical, user experience, } \\
\text { regulatory, and other issues } \\
\text { related to the research program. } \\
\text { (Review 32) }\end{array}$ \\
\hline $\begin{array}{l}\text { Design } \\
\text { approach }\end{array}$ & $\begin{array}{l}\text { The design approach } \\
\text { refers to the solution- } \\
\text { based method used in } \\
\text { developing mHealth } \\
\text { interventions. }\end{array}$ & $\begin{array}{l}\text { "Applying human-centred } \\
\text { methods in the design of e-health } \\
\text { solutions requires that designers } \\
\text { must take particular } \\
\text { considerations when patients and } \\
\text { healthcare professionals are } \\
\text { involved in the design process." } \\
\text { (Review 7) }\end{array}$ \\
\hline $\begin{array}{l}\text { Socio- } \\
\text { technical } \\
\text { aspects }\end{array}$ & $\begin{array}{l}\text { The socio-technical } \\
\text { aspects of } \\
\text { interventions are } \\
\text { defined as case- } \\
\text { specific interventions } \\
\text { based on qualitative } \\
\text { and empirical evidence } \\
\text { [46]. }\end{array}$ & $\begin{array}{l}\text { Furthermore, the overall } \\
\text { organizational socioeconomic } \\
\text { context of the clinical system } \\
\text { setup must be investigated. } \\
\text { (Review 2) }\end{array}$ \\
\hline $\begin{array}{l}\text { Design } \\
\text { evaluations }\end{array}$ & $\begin{array}{l}\text { "Evaluation is used to } \\
\text { refer to measures } \\
\text { taken, and analysis } \\
\text { performed to assess } \\
\text { (i) the interaction of } \\
\text { users or a health } \\
\text { system with the digital } \\
\text { health intervention } \\
\text { strategy, or } \\
\text { (ii) changes } \\
\text { attributable to the } \\
\text { digital health } \\
\text { intervention." [47] }\end{array}$ & $\begin{array}{l}\text { The application and evaluation of } \\
\text { this framework is demonstrated } \\
\text { through the use case of a mHealth } \\
\text { app that was designed to read the } \\
\text { results of the tuberculin skin test, } \\
\text { which is used to detect latent } \\
\text { tuberculosis infection (LTBI) and } \\
\text { for which a prototype was } \\
\text { available. } \\
\text { ( Review 30) }\end{array}$ \\
\hline
\end{tabular}

Data associated with each theme were read to see if the data truly supported the theme and how the themes work within a single article as well as across all articles. The process of naming themes entailed giving each theme a short and simple name. As a result, we extracted themes from the reviewed articles until we determined that no more themes might be derived from the data. The following section delves into the specific meanings of the set of analytical themes.

\section{Themes of Design Process for Improving user Engagement}

Any design process, according to [48], is "the specific series of events, actions, or methods by which a procedure or set of procedures is followed, in order to achieve an intended purpose, goal, or outcome" (p. 408). Fig. 2 depicts the design process for increasing user engagement with mHealth interventions, which consists of six analytically generated themes, each of which can be refined by a number of descriptive themes. Design goal, design target audience, design methods, design approach, socio-technical aspects, and design evaluations are the six analytical themes.

These analytical themes, as well as their descriptive themes, are discussed in greater detail in the results section that follows.

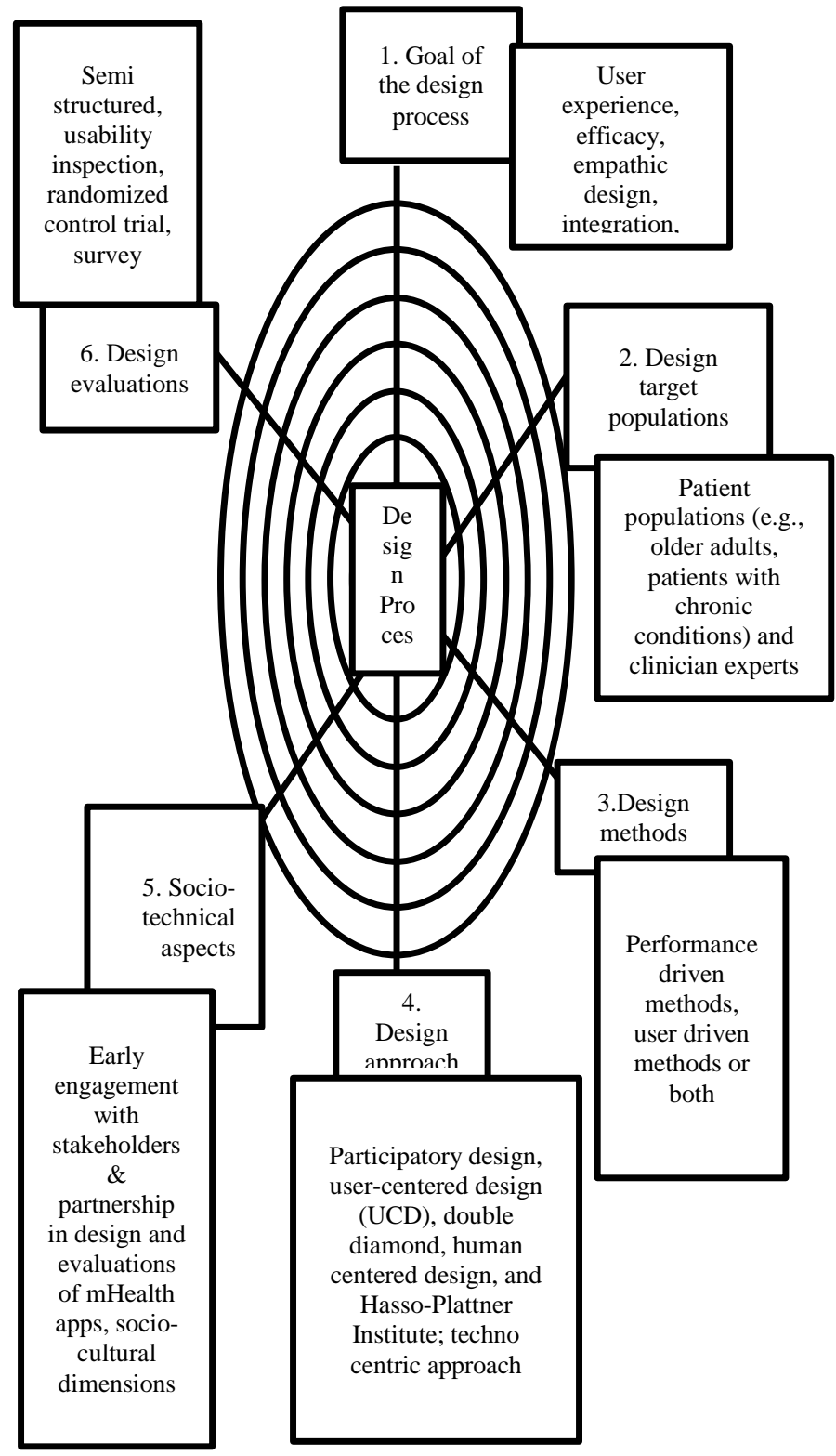

Fig. 2. Six Analytical Themes of Design Process. 


\section{RESUlts}

The six analytical themes provide a thorough examination of the mHealth design process with the goal of increasing user engagement with mHealth technology. They reveal a wide range of trends and discoveries. To describe the design process that can improve user engagement with mHealth interventions, six analytical themes were developed, each of which can be explained by several descriptive themes.

\section{A. Goal of the Design of mHealth Interventions}

Although there are numerous publicly available mHealth interventions, particularly mental health apps, as identified in the reviewed articles, current knowledge about the goals for designing such interventions is limited, particularly from a sociotechnical and user-centered perspective [49]. As a result, six descriptive themes related to design goals were identified: user experience, efficacy, empathic design, integrated, predictive, personalized, and inclusive. These are now described in greater detail.

1) User expereience: The reviewed articles stressed that mHealth interventions should not be medically approved solely on the basis of their effectiveness; the experience of users during the use process should also be evaluated [49] [50]. User experience should be researched and incorporated into the intervention design process [51] [52][53]. Although having a poor usability mHealth intervention may not have a discernible negative impact on users, the negative experience of users may prevent them from accepting and approving new mHealth technological interventions in the future [54][55][56][57].

2) Efficacy: The efficacy of mHealth interventions was frequently lauded in the reviewed articles. Many of the mHealth interventions described in the reviewed articles had observable outcomes [58][59][60] [61][62][63][64]. Despite the fact that the efficacy of mHealth interventions varied significantly across studies, all of the reviews indicated that mHealth was a viable concept with the prospective to improve patient health.

3) Empathic design: According to the reviewed articles, it is critical to consider the user's feelings toward mHealth products; users quickly lose interest when their feelings about using products are jeopardized [65][66]. The preference was for mobile device users to be paid attention to their feelings toward mHealth products [67] and to receive feedback on continuous monitoring data on user emotions while using mHealth products, such as how their feelings progress over time with mHealth product use [53], predicted possible causes and solutions [68][69][70].

4) Integrated: An mHealth platform should not be regarded as a stand-alone tool to be used in isolation. Collaboration among practitioners, other healthcare service components, communities, caregivers, patients, and their dependents is required in various aspects of mHealth interventions [59][7].

5) Predictive and personalized: Users of mHealth interventions desired not only automatically tailored information, but also the ability to personalize the mHealth intervention. The reviewed articles emphasized the importance of mHealth intervention users being able to choose when and how they receive SMS messages [72], setting goals for future use of the mHealth tool to personalized lifestyle with synchronous communication with a health care professional [73], and participating in identifying the mHealth system requirements [74][75].

6) Inclusive: According to the reviewed articles, inclusive health care systems based on mobile interventions (for example, in mental health) have frequently been viewed positively [76] in developing countries, [70][77] due to the obvious considerably large penetration rates of mobile technologies and the effectiveness of human resources. Furthermore, because of their intimate and confidential nature, mobile solutions can be effective in a culture that stigmatizes mental health issues [78]. The design processes examined in this review had the following goals: high-quality user experience, efficacy, empathic design, integration, "predictive and personalized," and inclusive. Fig. 3 depicts the distribution of design process goals in the articles reviewed.

The analysis of the design goals revealed that all mHealth intervention designs, in one way or another, attempt to achieve some goals. It was discovered that none of the mHealth intervention designs addressed a combination of all the goals used in this study. The most frequently addressed design goal is efficacy $(59 \%)$.

In 17 studies, user experience is the second most implemented design goal (53 percent). With 12 (38\%) and 11 (34\%), respectively, studies, inclusiveness and empathic design process ranked third and fourth in terms of most used design goals. With a total of $7(22 \%)$ studies and $5(16 \%)$ studies, integration and predictive and personalized were ranked fifth and sixth, respectively.

\section{B. Design Target Population}

The users who mHealth designers consider when developing mHealth interventions are referred to as the design target population. The reviewed articles reported three design target populations: patient population (e.g., older adults, patients with chronic conditions) [69][71][79][80]; or both (patient and clinician experts) [52][53].

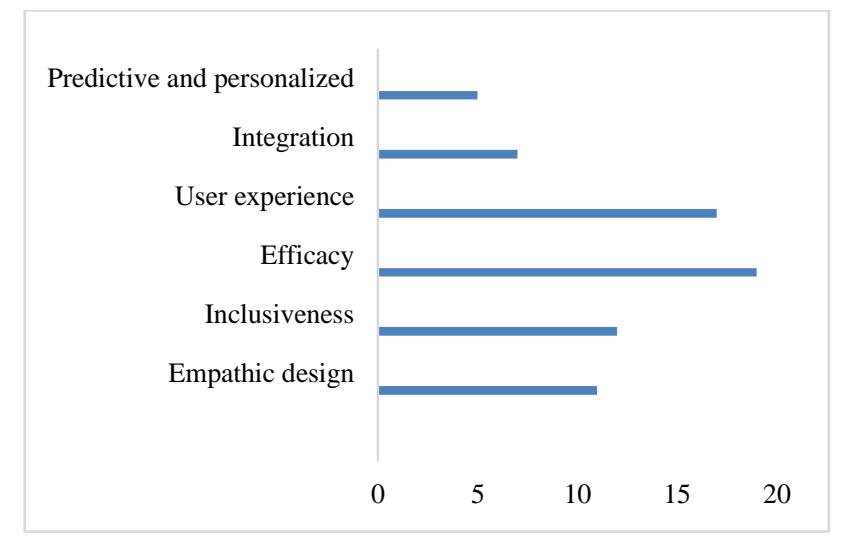

Fig. 3. mHealth Design Goals. 


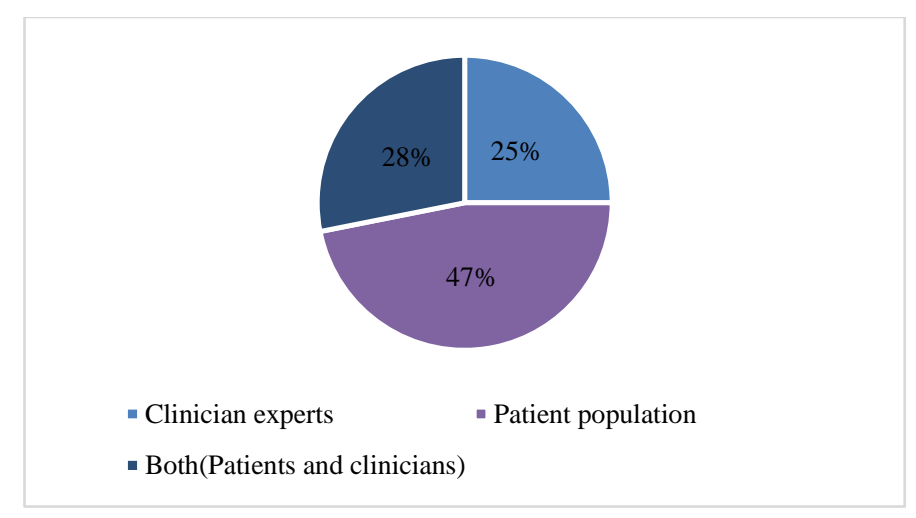

Fig. 4. mHealth Design Target Population.

The distribution of the articles across the mHealth design target population is depicted in Fig. 4. According to [81], mHealth projects frequently involve distinct stakeholders such as patient populations (e.g., older adults, patients with chronic conditions) and clinician experts, or both.

Eight studies $(25 \%)$ targeted the population of clinician experts, while nine articles $(28 \%)$ targeted the population of patients. Fifteen articles $(47 \%)$ were directed at both patients and clinicians.

\section{Design Methods}

Design methods are the methods or tools for designing that offer a variety of activities that a designer could use as part of an overall design process. Performance-driven methods, userdriven methods, and both were identified as three descriptive themes that could improve design methods (performance and user driven).

1) User driven methods: The reviewed articles underscored the importance of involving users from the start of the design process, to recognize, tap, and comprehend their explicit and implicit knowledge and ideas [50][65]. Userdriven innovation methods range from casual observations to collaborations and intensive user participation in co-creation processes [71][79].

2) Performance driven methods: Performance driven methods entail the use of expert analyses to generate a continuous flow of improvement ideas that are strongly focused on the desired results. Performance-driven methods are commonly used when it is difficult to extract ideas or information from potential users. Among the performance methods extracted from the reviewed articles were using machine learning model for predicting patients' ambience, feelings, psychological states, actions, environmental factors, and social context; demonstrating that the mobile diary tool can increase client adherence to therapeutic activities; collecting users' psychological, physiological, and activity information for mental health research; and using assisted cognitive behavioral therapy for insomnia [59][60].

3) User driven and performance driven methods: Some of the reviewed mHealth interventions used both user-driven and performance-based design methods, such as [52] personal health monitoring and feedback system for bipolar disorder patients, [53] autonomous, intelligent mobility aid for older adults, [72] SMS-based application to motivate behavior change among tobacco users, and [82] remote measurement technologies (RMT) to study central nervous system function.

\section{Comparative Analyses of the Design Methods, Design Goals and Design Target Population}

In terms of the three descriptive themes of design methods used in the reviewed articles, user driven methods and both (user driven and performance driven methods) share common design goals, whereas performance driven methods do not (Fig. 5).

Fig. 6 depicts the comparative analyses of design methods and design target populations presented in the review. It should come as no surprise that there is a strong correlation between the targeted population and the design methods used in the mHealth intervention design process. In 7 (22\%) of the articles aimed at patients and clinicians, a combination of user-driven and performance-driven methods were used. The user-driven method was used in $17(53 \%)$ of the reviewed articles that targeted both patients and clinicians, with 15 (47\%) focusing on patient populations and $2(6 \%)$ focusing on both patient and clinician populations. In $8(2 \%)$ of the clinician-targeted articles, the performance-driven method was used.

User-driven methods (53\%) were the most commonly used methods for the design process of mHealth interventions primarily aimed at patient populations, followed by performance-driven methods $(25 \%)$ aimed at clinician experts, and finally a combination of user-driven and performancedriven methods $(22 \%)$.

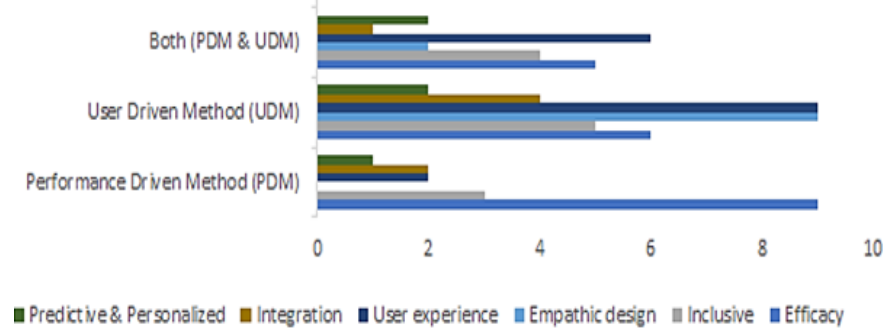

Fig. 5. Mobile Design Goals in different Design Methods.

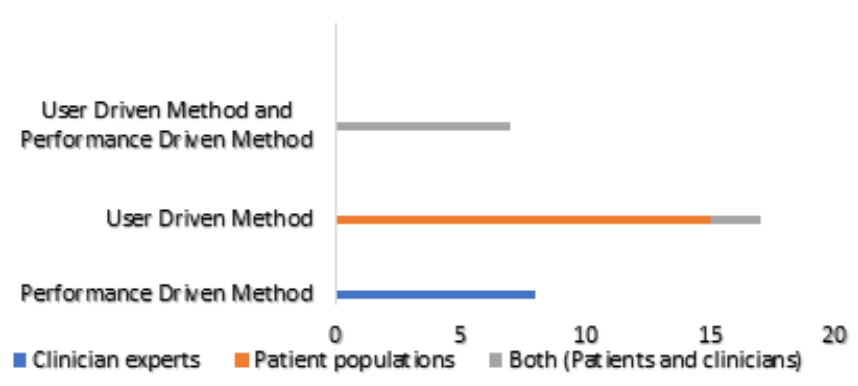

Fig. 6. Mobile Design Methods by Design Target Population. 


\section{E. Design Approach}

The solution-based method used in designing mHealth interventions is referred to as the design approach. The following six approaches were used in the reviewed articles: participatory design, user-centered design (UCD), double diamond, human centered design, and Hasso-Plattner Institute; and techno centric approach.

1) Participatory Design (PD): Participatory design (PD) is an approach that involves all stakeholders in the intervention design process and ensures that the interventions developed are usable and meet the needs of users. The author in [83] defines participatory design experience as a transition in mindset and perception toward people from designing for participants to designing with participants. It is the notion anyone can contribute towards the design process in some way and that, given the right tools, they can be both articulate and creative. According to [84], timely engagement and partnership with stakeholders is critical for mHealth implementation. The concept of partnership implies shared goals, shared accountability for outcomes, distinct accountabilities, and reciprocal obligations. The PD process consists of nine steps: introduction, analyses, idea generation, idea selection, prototyping, testing, adjusting, implementation, and evaluation [85]. In the reviewed articles, the PD approach was used in identifying the system requirements for the design of interventions for schizophrenia [71], trait anxiety in adults [66], breast cancer [67], self-monitoring behavior [69][74] and Ebola preparedness [70].

2) User-Centered Design (UCD): UCD is a process that places users at the center of product design and development. Its primary goal is to make interactive products usable by analyzing system usage and applying human factors and usability information and methods [86]. UCD is comprised of four steps: (1) comprehend and specify the context of use; (2) specify the user and organizational specifications; (3) develop design solutions; and (4) evaluate design in relation to specifications [87]. The UCD approach was used in the reviewed articles to identify system requirements for the design of an intervention for multiple sclerosis [82], mental illness management [51][52], intelligent mobility aid for older adults [53], support for adolescents coping with chronic pain [61], behaviour patterns [80][88] and self-management [82][89].

3) Double Diamond (DD): The Design Council (2007) developed the Double Diamond approach, which is based on the application of design thinking in businesses and innovation designs and has four phases (discovery, definition, development, and delivery) ${ }^{1}$. There was limited use of the Double Diamond approach in the review articles, with only [77] using it to improve healthcare delivery, particularly in underserved contexts. Human-centered design and the HassoPlattner Institute were two other design thinking approaches used in the reviewed articles. These approaches are described in the following sections.

4) Human centered design: Innovation, Design Engineering Organization (IDEO) created the human-centered design (HCD) approach. Hearing, Creating, and Delivering are the three phases of $\mathrm{HCD}^{2}$. The author in [90] states that "HCD will assist one in hearing the needs of users in new ways, creating innovative solutions to meet users' needs, and delivering answers with financial sustainability in mind." (Page 7) HCD was used in the reviewed articles to create a patient-centered e-health solution for patients receiving weight reduction therapies [50].

5) Hasso-Plattner Institute(HPI): The Hasso-Plattner Institute's approach ${ }^{3}$ consists of six steps: 'Understand,' 'Observe,' 'Point of View,' 'Ideate,' 'Prototype,' and 'Test.' In the reviewed articles, HPI was used to improve the testing of latent tuberculosis infection by health workers [75].

6) Techno-centric appraoch: The term "technocentric approach" refers to a point of view that emphasizes technological aspects of designs. The primary distinction between the techno-centric approach and the other approaches described in the reviewed articles is that the other approaches are focused on understanding potential users, which is typically discovered through research process by conducting comprehensive analysis of potential users' behaviours, actions, and desires. The techno-centric approach, on the other hand, is based on "technology-push," in which designers focus on technology first, after which try for implementations for it. [91].

In the reviewed articles, an example of a techno-centric approach was used in design of mHealth to predict patients' ambience, feelings, psychological states, actions, environmental factors, and social context by using machine learning models [58], to improve the design of client adherence to therapeutic activities [59], to collect users' psychological, physiological, and activity information [62][64], and to promote postpartum weight loss [73].

Fig. 7 presents the major design process approaches employed in the design of mHealth interventions for user engagement.

The articles under consideration took more than one approach. Overall, $21(66 \%)$ of the 32 reviewed articles used a participatory design approach, while $8(25 \%)$ used a technocentric approach, and $3(9 \%)$ used design thinking (whether double diamond, human centered design, or Hasso-Plattner Institute), with that being the least used approach in the articles reviewed, as shown in Fig. 7. This suggests that knowledge about how design thinking can impact mHealth intervention competencies is either still developing or has a minor impact in mHealth designs. Scholars, on the other hand, advocate for more research into how design thinking influences innovation design processes and methods [92].

\footnotetext{
${ }^{2}$ https://designthinking.ideo.com/

http://www.hpi.uni-potsdam.de/d_school/designthinking
}

${ }^{1}$ http://www.designcouncil.org.uk 


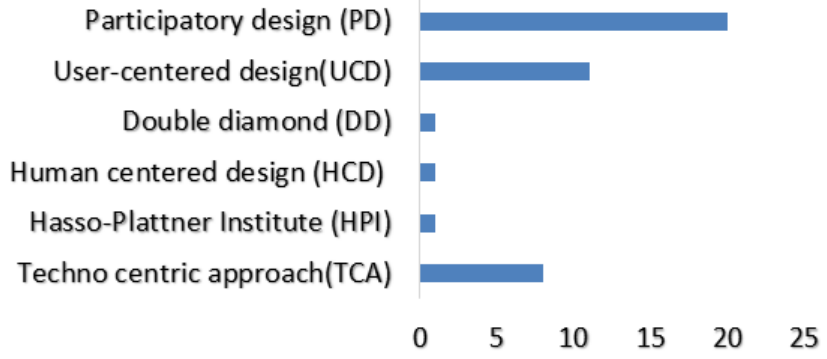

Fig. 7. mHealth Design Approach.

\section{F. Socio-technical Aspects}

Socio-technical aspects describe case-specific interventions based on qualitative and empirical evidence and include three descriptive elements such as early user engagement in design, evaluations of mHealth interventions, and understanding users' socio-cultural context.

Eleven studies (34\%) used qualitative design method to examine various components of the system, including personal traits of use as well as larger issues of patient-healthcaresystem interaction [61]. Examples include early user involvement and identifying and managing relationships between stakeholders in the design of mHealth interventions [71][77], user involvement in the evaluation stages of mHealth development [8][73], and incorporation of users' socio-cultural contexts into the design of mHealth interventions [51] [65]. The sociocultural contexts of mHealth intervention use, according to [49], are among the most difficult aspects of developing mHealth solutions and designing for technology acceptance and adoption. Two of the most important sociocultural factors to consider before developing any mHealth solution are the position of users in the design of systems and products, as well as cultural differences. Thus, a culturerooted design approach is considered to be the best way to actually connect and communicate cultural identity, significance, values, and tradition [93]. Of the reviewed articles, $21(66 \%)$ did not explicitly discuss sociotechnical aspects in the design process of mHealth interventions.

\section{G. Design Evaluations}

Design evaluations are the processes that are used to determine whether mHealth interventions work as intended for end users.

In the 7 of the 32 reviewed articles (22\%) that discussed evaluation, the following four techniques were used to evaluate design: semi structured interviews, usability inspection, survey, and randomized control trial. Table II summarizes the evaluation techniques, their benefits and drawbacks, and the design goals.

These various evaluation techniques in Table II can be divided into two categories: formative and summative. Formative evaluations, according to [47], are studies that aim to inform the development and design of effective intervention techniques. Summative evaluations, on the other hand, are techniques carried out at the completion of an intervention (or at the end of each stage of the intervention) to verify the degree to which expected results were achieved.
TABLE II. EVALUATION TECHNIQUES AND DESIGN GOALS AS IDENTIFIED IN THE REVIEWED ARTICLES

\begin{tabular}{|c|c|c|c|c|}
\hline $\begin{array}{l}\text { Article } \\
\text { s }\end{array}$ & $\begin{array}{l}\text { Evaluation } \\
\text { techniques }\end{array}$ & Descriptions & $\begin{array}{l}\text { Design } \\
\text { Goals }\end{array}$ & Considerations \\
\hline $\begin{array}{l}\text { "Ref. } \\
\text { [65]" }\end{array}$ & $\begin{array}{l}\text { Semi } \\
\text { structured }\end{array}$ & $\begin{array}{l}\text { This technique } \\
\text { provides a } \\
\text { channel for the } \\
\text { distribution of } \\
\text { UXs and } \\
\text { sensations in } \\
\text { the design } \\
\text { process of } \\
\text { mobile phone } \\
\text { video } \\
\text { messaging } \\
\text { smoking } \\
\text { cessation } \\
\text { intervention } \\
\text { and } \\
\text { multimedia } \\
\text { messaging } \\
\text { depression } \\
\text { prevention } \\
\text { intervention. }\end{array}$ & $\begin{array}{l}\text { Empathic } \\
\text { design: }\end{array}$ & $\begin{array}{l}\text { Benefits: inform } \\
\text { changes to } \\
\text { increase } \\
\text { satisfaction, } \\
\text { interaction, and } \\
\text { adapt to end- } \\
\text { user needs; } \\
\text { identify a variety } \\
\text { of issues } \\
\text { associated with } \\
\text { intervention use } \\
\text { Drawbacks: } \\
\text { subject to bias, } \\
\text { especially if } \\
\text { there isn't } \\
\text { enough time to } \\
\text { collect and } \\
\text { transcribe data } \\
\text { and it takes more } \\
\text { than one person } \\
\text { to decide on the } \\
\text { themes } \\
\text { generating. }\end{array}$ \\
\hline $\begin{array}{l}\text { "Ref. } \\
\text { [79]" }\end{array}$ & $\begin{array}{l}\text { Usability } \\
\text { inspection }\end{array}$ & \multirow{2}{*}{$\begin{array}{l}\text { The goal of } \\
\text { this technique } \\
\text { is to first, } \\
\text { incorporate } \\
\text { real-time user } \\
\text { experience by } \\
\text { delivering a } \\
\text { task to users } \\
\text { and observing } \\
\text { them as they } \\
\text { complete the } \\
\text { task ... and } \\
\text { second, refinin } \\
\text { g the content, } \\
\text { potential } \\
\text { functionality, } \\
\text { and interface } \\
\text {... based on } \\
\text { user feedback. }\end{array}$} & $\begin{array}{l}\text { User } \\
\text { experience } \\
:\end{array}$ & \multirow{2}{*}{$\begin{array}{l}\text { Benefits: allows } \\
\text { to determine } \\
\text { which features } \\
\text { of the } \\
\text { intervention } \\
\text { influenced user } \\
\text { engagement in } \\
\text { real time. } \\
\text { Drawbacks: may } \\
\text { place a mental } \\
\text { burden on the } \\
\text { users, making it } \\
\text { difficult for the } \\
\text { observer to } \\
\text { analyze the data } \\
\text { collected. }\end{array}$} \\
\hline $\begin{array}{l}\text { "Ref. } \\
\text { [8]" }\end{array}$ & $\begin{array}{l}\text { Usability } \\
\text { inspection }\end{array}$ & & $\begin{array}{l}\text { User } \\
\text { experience } \\
\text { and } \\
\text { Empathic } \\
\text { design }\end{array}$ & \\
\hline $\begin{array}{l}\text { "Ref. } \\
\text { [67]" }\end{array}$ & $\begin{array}{l}\text { Randomized } \\
\text { controlled } \\
\text { trial }\end{array}$ & $\begin{array}{l}\text { A planned } \\
\text { experiment } \\
\text { that compares } \\
\text { the } \\
\text { effectiveness } \\
\text { of an } \\
\text { intervention. }\end{array}$ & $\begin{array}{l}\text { Empathic } \\
\text { design } \\
\text { process } \\
\text { and } \\
\text { inclusiven } \\
\text { ess }\end{array}$ & \multirow{2}{*}{$\begin{array}{l}\text { Benefits: high } \\
\text { standard of } \\
\text { study design } \\
\text { Drawbacks: } \\
\text { Ethical concerns } \\
\text { and the } \\
\text { difficulty of } \\
\text { randomizing } \\
\text { subjects }\end{array}$} \\
\hline $\begin{array}{l}\text { "Ref. } \\
\text { [73]" }\end{array}$ & $\begin{array}{l}\text { Randomized } \\
\text { controlled } \\
\text { trial }\end{array}$ & $\begin{array}{l}\text { Randomized } \\
\text { controlled, } \\
\text { trial to test the } \\
\text { efficacy of a } \\
\text { SmartPhone- } \\
\text { based } \\
\text { intervention to } \\
\text { promote } \\
\text { postpartum } \\
\text { weight loss. }\end{array}$ & $\begin{array}{l}\text { Efficacy, } \\
\text { predictive } \\
\text { and } \\
\text { personaliz } \\
\text { ed }\end{array}$ & \\
\hline
\end{tabular}




\begin{tabular}{|c|c|c|c|c|}
\hline $\begin{array}{l}\text { "Ref. } \\
{[77] "}\end{array}$ & Survey & $\begin{array}{l}\text { Structured } \\
\text { questionnaires } \\
\text { with many } \\
\text { questions to } \\
\text { elicit } \\
\text { comprehensive } \\
\text { information } \\
\ldots .\end{array}$ & $\begin{array}{l}\text { User } \\
\text { experience } \\
\text {, efficacy } \\
\text { and } \\
\text { inclusiven } \\
\text { ess }\end{array}$ & $\begin{array}{l}\text { Benefit: It may } \\
\text { be less } \\
\text { expensive than } \\
\text { alternatives. } \\
\text { Drawbacks Does } \\
\text { not give an } \\
\text { indication of the } \\
\text { sequence of } \\
\text { events because } \\
\text { they are carried } \\
\text { out at one time } \\
\text { point. }\end{array}$ \\
\hline $\begin{array}{l}\text { "Ref. } \\
{[75] "}\end{array}$ & $\begin{array}{l}\text { Usability } \\
\text { inspection }\end{array}$ & $\begin{array}{l}\text { Incorporate } \\
\text { real-time user } \\
\text { experience by } \\
\text { delivering a } \\
\text { task to users } \\
\text { and observing } \\
\text { them as they } \\
\text { complete the } \\
\text { task in the } \\
\text { design of a } \\
\text { mHealth } \\
\text { intervention } \\
\text { and analyzing } \\
\text { and reporting } \\
\text { the results } \\
\text { through the } \\
\text { lens of the } \\
\text { combined } \\
\text { Information } \\
\text { Systems } \\
\text { Research } \\
\text { (ISR) } \\
\text { framework and } \\
\text { design } \\
\text { thinking } \\
\text { approach. }\end{array}$ & $\begin{array}{l}\text { User } \\
\text { experience } \\
\text {, efficacy, } \\
\text { predictive } \\
\text { and } \\
\text { personaliz } \\
\text { ed and } \\
\text { some } \\
\text { extent } \\
\text { empathic } \\
\text { design } \\
\text { process }\end{array}$ & $\begin{array}{l}\text { Benefits: allows } \\
\text { to determine } \\
\text { which features } \\
\text { of the } \\
\text { intervention } \\
\text { influenced user } \\
\text { engagement, } \\
\text { effective and } \\
\text { usable in real } \\
\text { time. } \\
\text { Drawbacks: may } \\
\text { place a mental } \\
\text { burden on the } \\
\text { users. }\end{array}$ \\
\hline
\end{tabular}

\section{H. Checklist of Design Process to Improve user Engagement}

We developed a checklist based on a comprehensive evaluation of the 32 articles that considers 6 themes of the design process and the corresponding implementations. There were 16 items reported that improve user engagement in total, and we provide explanations and illustrations as a basis for future research (Table III).

TABLE III. CHECKLIST OF DESIGN PROCESS THAT ENHANCE USER ENGAGEMENT

\begin{tabular}{|c|c|c|}
\hline Themes & \multicolumn{2}{|c|}{ Criteria } \\
\hline Goal of the design & & $\begin{array}{l}\text { Outline in a clear statement the goals of the } \\
\text { design. } \\
\text { Identify metrics that will allow mHealth } \\
\text { designers and developers to track progress and } \\
\text { determine when the design's goals have been } \\
\text { met. }\end{array}$ \\
\hline $\begin{array}{l}\text { Design target } \\
\text { populations }\end{array}$ & $\begin{array}{l}3 . \\
4 . \\
5 .\end{array}$ & $\begin{array}{l}\text { Identify stakeholders and their roles in the } \\
\text { mobile health design. } \\
\text { Include stakeholders with a diverse set of } \\
\text { skills and perspectives and } \\
\text { Involve all stakeholders from the beginning } \\
\text { and throughout the design process of mHealth } \\
\text { interventions. } \\
\text { Examine the ethical issues surrounding }\end{array}$ \\
\hline
\end{tabular}

\begin{tabular}{|c|c|c|}
\hline & 7. & $\begin{array}{l}\text { participant enrollment, such as obtaining } \\
\text { consent and maintaining confidentiality. }\end{array}$ \\
\hline Design method & 9. & $\begin{array}{l}\text { Base the design on a clear understanding of } \\
\text { the users, tasks performance, and } \\
\text { environments. } \\
\text { Provide task performance and environment } \\
\text { information tailored to the user's preferences. }\end{array}$ \\
\hline Design approach & $\begin{array}{l}10 . \\
11 .\end{array}$ & $\begin{array}{l}\text { Use an iterative design process. } \\
\text { Ensure that the design process considers the } \\
\text { entire user experience, flow and aesthetics. }\end{array}$ \\
\hline $\begin{array}{l}\text { Socio-technical } \\
\text { aspects }\end{array}$ & $\begin{array}{c}13 . \\
14 .\end{array}$ & $\begin{array}{l}\text { Use Techno-social design (TSD) and culture } \\
\text { centered design (CCD) to incorporate users' } \\
\text { socio-cultural contexts into the design of } \\
\text { mHealth interventions. } \\
\text { Co-designing with users to understand their } \\
\text { values is preferable to designing for users. } \\
\text { Identify the barriers and facilitators of } \\
\text { intervention participation among study } \\
\text { participants. Individual-level structural } \\
\text { barriers or facilitators, as well as other factors } \\
\text { that may limit a user's ability to engage with } \\
\text { the intervention, should be addressed. }\end{array}$ \\
\hline Design evaluations & $\begin{array}{c}15 . \\
16 .\end{array}$ & $\begin{array}{l}\text { Assess how users felt about the intervention or } \\
\text { how satisfied they were with it. } \\
\text { Describe the evaluation techniques used (for } \\
\text { example, usability testing), along with the } \\
\text { target group(s). } \\
\text { Determine whether the mHealth intervention } \\
\text { incurred costs that were proportionate to the } \\
\text { benefits of the design's goal. }\end{array}$ \\
\hline
\end{tabular}

\section{DISCUSSION}

In response to several requests for more information on how to design mHealth interventions that effectively engage their users and measure engagement, this systematic literature review paints a picture of how these design processes address user engagement and their socio-cultural contexts. As a methodological framework, user-centered design is used, and related projects that explicitly apply that framework are presented. Based on the articles we reviewed, we used thematic synthesis to identify design processes that increased user engagement with mHealth interventions. This paper discusses six analytical themes related to the design process that can strengthen user engagement with mHealth interventions. We created a design process checklist that improves user engagement to encourage better application of the study's findings to future mHealth intervention development. This tool contains 16 evidence-based items that are clearly described for mHealth intervention designers and developers.

This research yields four major findings. To begin, a robust design process for user engagement with mHealth that incorporates users' socio-cultural contexts into the design of mHealth interventions is required. It has been established that the socio-cultural contexts associated with user engagement are important factors to consider when attempting to achieve user engagement with technology [11]. Techno-social design (TSD) and culture-centered design (CCD) are design principles that emphasize users' social and cultural backgrounds [93]. CCD focuses on the target user and their specific cultural situation. It offers a complementary, rather than diametrically opposed perspective to existing design 
methodologies [93]. These design approaches would incorporate user feedback into the mHealth intervention design process. Ethnographic observation or any other methods of describing the mechanism of user engagement with mHealth applications and designing engaging mHealth applications could be used in user research.

Second, the systematic review of literature revealed that mHealth designs should explicitly use user- or humancentered design approaches and involve users from the beginning to understand their needs, as well as throughout the mHealth design process. This finding is consistent with usercentered design interpretations and requirements, which assert that such a process must involve users and understand their needs early and throughout an iterative process.

Third, mHealth initiatives could conduct initial evaluations by soliciting user feedback (for example, through semistructured interviews or surveys), users interacting with mHealth application prototypes using the usability inspection method and asking detailed questions of what users recognized from the prototype and how it engaged them during user testing.

Finally, more collaboration between patient and clinician populations in mHealth design should be allowed in all mHealth projects. Involvement and engagement of stakeholders (patients and clinicians) in research teams should be encouraged in order to foster an appropriate partnership. To keep the use of mHealth tools relevant, [94] states that a technology-enabled health care partnership with patients and clinicians is required.

We acknowledge some limitations in our work, namely that the literature on mHealth design processes is primarily focused on efficacy and general user experience, as well as other design objectives, with eleven of 32 articles emphasizing the importance of identifying socio-cultural contexts of the user group in the mHealth design process. The articles, however, did not provide extensive and clear guidance, frameworks, or methods for uncovering such socio-cultural contexts in order to improve user engagement with mHealth technology. There was little evidence of these design processes being evaluated (as opposed to mHealth intervention evaluations). As a result, there is a gap in understanding and examining the factors that influence mHealth engagement, acceptance, and usage processes within the mHealth design process. This gap explains why mHealth interventions are poorly accepted and have a limited impact.

Despite these limitations and constraints, we believe the research findings have significant implications, prompting us to make the following recommendations.

1) An ideal mHealth app user engagement framework should capture the users' sociocultural contexts in order to assist mHealth developers and implementers in determining which aspects of the interaction with technology engage, or fail to engage, users. This would overcome the limitations of previous frameworks by covering the design of mHealth apps for user engagement.
2) To assess user engagement with an app, mHealth evaluation criteria should be clear, concise, specific, and objective. It is also critical to assess user engagement early in the design process of mHealth interventions and consider improving the user-centered design framework and perhaps using other frameworks, particularly techno-social design (TSD) and cultural centered design (CCD), that consider design principles emphasizing users' social and cultural contexts in the design of mHealth interventions.

3) A comprehensive objective mHealth user engagement design framework requires future testing on various platforms across many mHealth implementations to determine a lowburden approach to improve user engagement cheaply and efficiently.

4) There are contributions about theory-based mHealth systems for, user-engaged mHealth interventions based on behavioural techniques. However, the reviews emphasize the need to develop a framework that will employ processes and tools that uncover socio-cultural contexts of end users into the design of mHealth technologies and encompasses all the areas that this systematic review identified as important for user engagement with mHealth.

\section{CONCLUSION}

This systematic review of the literature looks at articles that focus on the design processes of mHealth interventions. We provided a thorough comparison of the design methods and who the design targets for mHealth design interventions, highlight trends in the mobile design process, targeting patients and/or clinicians, including design goals implemented alongside the mHealth interventions, design process approach used, sociotechnical aspects of the systems, and mHealth intervention evaluations. The strengths and weaknesses of existing mHealth design processes for user engagement are discussed, and recommendations for future research in these areas are made. We discovered that only a few of the reviewed articles considered the evaluation of mHealth interventions, and the majority of the articles did not consider a framework that will incorporate processes and tools that uncover end users' socio-cultural contexts into the design of mHealth technologies. According to the findings, the participatory approach of user-centered designs was most frequently used in the review articles.

\section{REFERENCES}

[1] R. Heeks. Information systems and developing countries: Failure, success, and local improvisations. The information society, 18(2), 2002, pp. 101-112.

[2] P. Bhatt, A.J. Ahmad, \& M. A. Roomi. Social innovation with open source software: User engagement and development challenges in India. Technovation, 52, 2016, pp. 28-39.

[3] A. K. Böhm, M. L. Jensen, M. R. Sørensen, \& T. Stargardt, . Real-world evidence of user engagement with mobile health for diabetes management: longitudinal observational study. JMIR mHealth and uHealth, 8(11), 2020. e22212.

[4] A. Grady, S. Yoong, R. Sutherland, H. Lee, N. Nathan, \& L. Wolfenden, L. Improving the public health impact of eHealth and mHealth interventions. Australian and New Zealand journal of public health, 42(2), 2018. pp.118-119. 
[5] M. Cherubini, \& N. Oliver,. A refined experience sampling method to capture mobile user experience. 2009. arXiv preprint arXiv:0906.4125.

[6] L.A. Kappelman, \& E. R. McLean. User engagement in the development, implementation, and use of information technologies. In HICSS (4) 1994. pp. 512-521.

[7] S. Attfield, G. Kazai, M. Lalmas, \& B. Piwowarski. Towards a science of user engagement (position paper). In WSDM workshop on user modelling for Web applications 2011. pp. 9-12.

[8] R. Schnall, M. Rojas, S. Bakken, W. Brown, A. Carballo-Dieguez, M. Carry, ... \& J. Travers, J. A user-centered model for designing consumer mobile health (mHealth) applications (apps). Journal of biomedical informatics, 60, 2016. Pp. 243-251.

[9] K.E. Curtis, S. Lahiri, \& K.E. Brown. Targeting parents for childhood weight management: development of a theory-driven and user-centered healthy eating app. JMIR mHealth and uHealth, 3(2), 2015. e3857.

[10] F. Verhoeven, K. Tanja-Dijkstra, N. Nijland, G. Eysenbach, \& van L. Gemert-Pijnen, . Asynchronous and synchronous teleconsultation for diabetes care: a systematic literature review. Journal of diabetes science and technology, 4(3), 2010. pp. 666-684.

[11] T. McCurdie, S. Taneva, M. Casselman, M. Yeung, C. McDaniel, W. Ho, \& J. Cafazzo. mHealth consumer apps: the case for user-centered design. Biomedical instrumentation \& technology, 46(2), 2012. 49.

[12] P. CISION. Motivating Patients to Use Smartphone Health Apps. 2015. URL: http://www. prweb. com/releases/2011/04/prweb5268884. htm [accessed 2015-08-10].

[13] G.C. Machado, M.B. Pinheiro, H. Lee, O.H. Ahmed, P. Hendrick, C. Williams, \& S.J. Kamper. Smartphone apps for the self-management of low back pain: A systematic review. Best Practice \& Research Clinical Rheumatology, 30(6), 2016. Pp.1098-1109.

[14] S. Taki, S. Lymer, C.G. Russell, K. Campbell, R. Laws, K.L. Ong, ... \& E. Denney-Wilson, E. Assessing user engagement of an mHealth intervention: development and implementation of the growing healthy app engagement index. JMIR mHealth and uHealth, 5(6), 2017. e7236.

[15] O. Perski, D. Crane, E. Beard, \& J. Brown. Does the addition of a supportive chatbot promote user engagement with a smoking cessation app? An experimental study. Digital health, 5, 2019. 2055207619880676.

[16] N. Wickramasinghe. Understanding the mHealth implementation and adoption impact: a FVM perspective. Electron. Sci. Technol. Appl, 5(2), 2018. p.1-9.

[17] N.A. Shozi, D. Pottas, \& N. Mostert-Phipps. A socio-technical perspective on the use of mobile phones for remote data collection in home community based care in developing countries. In International Conference on e-Infrastructure and e-Services for Developing Countries 2011. pp. 135-145. Springer, Berlin, Heidelberg.

[18] K. Tabi, A.S. Randhawa, F. Choi, Z. Mithani, F. Albers, M. Schnieder, ... \& M. Krausz. Mobile apps for medication management: review and analysis. JMIR mHealth and uHealth, 7(9), 2019. e13608.

[19] C. Avgerou, \& G. Walsham. Information technology in context: Implementing systems in the developing world. 2000. Brookfield, VT: Ashgate Publishing.

[20] M. R Hoque, M.S. Rahman, N.J. Nipa, \& M.R. Hasan. Mobile health interventions in developing countries: A systematic review. Health Informatics Journal, 2020. 1460458220937102.

[21] D. Zurovac, A.O. Talisuna, \& R.W. Snow. Mobile phone text messaging: tool for malaria control in Africa. PLoS medicine, 9(2), 2012. e1001176.

[22] C.B. Aranda-Jan, N. Mohutsiwa-Dibe, \& S. Loukanova, S. Systematic review on what works, what does not work and why of implementation of mobile health (mHealth) projects in Africa. BMC public health, 14(1), 2014. pp.1-15.

[23] E.F. Krah, \& J.G. de Kruijf, Exploring the ambivalent evidence base of mobile health (mHealth): A systematic literature review on the use of mobile phones for the improvement of community health in Africa. Digital health, 2, 2016. 2055207616679264.

[24] C.S. Hall, E. Fottrell, S. Wilkinson \& P. Byass. Assessing the impact of mHealth interventions in low-and middle-income countries-what has been shown to work?. Global health action, 7(1), 2014. 25606.
[25] C. Granja, W. Janssen \& M.A. Johansen. Factors determining the success and failure of eHealth interventions: systematic review of the literature. Journal of medical Internet research, 20(5), 2018. e10235.

[26] T.D. Manda \& Y. Msosa,. Socio-technical arrangements for mhealth: Extending the mobile device use and adoption framework. In International Conference on e-Infrastructure and e-Services for Developing Countries. 2012. pp. 208-217. Springer, Berlin, Heidelberg.

[27] J. G. Kahn, J.S. Yang, \& J.S. Kahn. 'Mobile'health needs and opportunities in developing countries. Health affairs, 29(2), 2010. pp.252-258.

[28] J. Kaasbøll, \& J. L. Nhampossa. Transfer of public sector information systems between developing countries: south-south cooperation. Social Implications of Computers in Developing Countries, Bangalore. 2002.

[29] J. H. Wu, S.C. Wang \& L.M. Lin. Mobile computing acceptance factors in the healthcare industry: A structural equation model. International journal of medical informatics, 76(1), 2007. pp.66-77.

[30] E.B. Tate, D. Spruijt-Metz, G. O'Reilly, M. Jordan-Marsh, M. Gotsis, M.A. Pentz, \& G. F. Dunton. mHealth approaches to child obesity prevention: successes, unique challenges, and next directions. Translational behavioral medicine, 3(4), 2013. pp.406-415.

[31] R. Harris, \& R. Davison. Anxiety and involvement: Cultural dimensions of attitudes toward computers in developing societies. In Global perspective of information technology management 2002. pp. 234-259. IGI Global.

[32] G. Hofstede, G. Dimensionalizing cultures: The Hofstede model in context. Online readings in psychology and culture, 2(1), 2011. pp.3070919.

[33] J. Braa, O. Hanseth, A. Heywood, W. Mohammed, \& V. Shaw. Developing health information systems in developing countries: the flexible standards strategy. Mis Quarterly, 2007. pp.381-402.

[34] T. Ikwunne, L. Hederman, \& P.J Wall. Designing Mobile Health for User Engagement: The Importance of Socio-Technical Approach. 2021. arXiv preprint arXiv:2108.09786.

[35] R. Braun, C. Catalani, J. Wimbush, \& D. Israelski, D. Community health workers and mobile technology: a systematic review of the literature. PloS one, 8(6), 2013. e65772.

[36] K. Overbeeke, T. Djajadiningrat, C. Hummels, S. Wensveen, \& J. Prens. Let's make things engaging. In Funology . 2003.pp. 7-17. Springer, Dordrecht.

[37] H. L. O'Brien, \& E.G. Toms. The development and evaluation of a survey to measure user engagement. Journal of the American Society for Information Science and Technology, 61(1), 2010. pp.50-69.

[38] K. Doherty, K \& G. Doherty. Engagement in HCI: conception, theory and measurement. ACM Computing Surveys (CSUR), 51(5),2018. pp. $1-39$.

[39] B. Laurel. Computers as theatre reading. Mas: Addison-Wesley Publishing Company. 1991.

[40] W. Quesenbery. Dimensions of usability. Content and complexity: Information design in technical communication. 2003.

[41] P. Saariluoma. Explanatory frameworks for interaction design. In. A. Pirhonen, P. Saariluoma, H Isomaki, \& C. Roast (Eds.) Future interaction design 2005.pp. 67-83.

[42] H.L. O'brien, \& E.G. Toms. Examining the generalizability of the User Engagement Scale (UES) in exploratory search. Information Processing \& Management, 49(5), 2013. pp.1092-1107.

[43] J. McCarthy, \& P. Wright. Technology as experience. interactions, 11(5), 2004. pp.42-43.

[44] S. J. Flaherty, M. McCarthy, A.M. Collins, C. McCafferty, \& F. M. McAuliffe. Exploring engagement with health apps: the emerging importance of situational involvement and individual characteristics. European Journal of Marketing.2021.

[45] V. Braun \& V. Clarke. Using thematic analysis in psychology. Qualitative Research in Psychology, 3(2), 2006. pp.77-101. Available at: http://eprints.uwe.ac.uk/11735.

[46] L.L. Novak, R. J. Holden, S. H. Anders, J.Y. Hong, \& B.T. Karsh, B. Using a sociotechnical framework to understand adaptations in health IT implementation. International journal of medical informatics, 82(12), 2013. e331-e344. 
[47] World Health Organization. Monitoring and evaluating digital health interventions: a practical guide to conducting research and assessment.2016.

[48] K. Best. Design management: managing design strategy, process and implementation. AVA publishing. 2006.

[49] B. Aryana, L. Brewster \& J.A. Nocera. Design for mobile mental health: an exploratory review. Health and Technology, 9(4), 2019. pp.401-424.

[50] A. Das, \& D. Svanæs,. Human-centred methods in the design of an ehealth solution for patients undergoing weight loss treatment. International journal of medical informatics, 82(11), 2013. pp.10751091.

[51] G. Marcu, J.E. Bardram, \& S. Gabrielli. A framework for overcoming challenges in designing persuasive monitoring and feedback systems for mental illness. In 2011 5th International Conference on Pervasive Computing Technologies for Healthcare (PervasiveHealth) and Workshops 2011.pp. 1-8. IEEE.

[52] J. E. Bardram, M. Frost, K. Szántó, M. Faurholt-Jepsen, M. Vinberg, \& L.V. Kessing. Designing mobile health technology for bipolar disorder: a field trial of the monarca system. In Proceedings of the SIGCHI conference on human factors in computing systems 2013. pp. 26272636.

[53] A. K. Bright \& L. Coventry, L. Assistive technology for older adults: psychological and socio-emotional design requirements. In Proceedings of the 6th International Conference on Pervasive Technologies Related to Assistive Environments 2013.pp. 1-4.

[54] M. Price, E.K Yuen, E.M. Goetter, J.D. Herbert, E.M. Forman, R. Acierno, and K.J Ruggiero. mHealth: a mechanism to deliver more accessible, more effective mental health care. Clinical psychology \& psychotherapy, 21(5), 2014. pp.427-436.

[55] D.D. Luxton, R.A. McCann, N.E. Bush, M.C. Mishkind, and G.M. Reger. mHealth for mental health: Integrating smartphone technology in behavioral healthcare. Professional Psychology: Research and Practice, 42(6), 2011. p.505.

[56] A. Gaggioli, G. Pioggia, G. Tartarisco, G. Baldus, D. Corda, P. Cipresso, \& G. Riva. A mobile data collection platform for mental health research. Personal and Ubiquitous Computing, 17(2), 2013. pp. 241-251.

[57] J.F. Pelletier, M. Rowe, N. François, J. Bordeleau, \& S. Lupien. No personalization without participation: on the active contribution of psychiatric patients to the development of a mobile application for mental health. BMC Medical Informatics and Decision Making, 13(1), 2013. pp.1-8.

[58] M.N. Burns, M. Begale, J. Duffecy, D. Gergle, C.J. Karr, E. Giangrande, \& D.C. Mohr. Harnessing context sensing to develop a mobile intervention for depression. Journal of medical Internet research, 13(3), 2011. e55.

[59] M. Matthews \& G. Doherty. In the mood: engaging teenagers in psychotherapy using mobile phones. In Proceedings of the SIGCHI Conference on Human Factors in Computing Systems 2011.pp. 29472956.

[60] S. C. Reid, S.D. Kauer, S.J. Hearps, A.H. Crooke, A.S. Khor, L.A Sanci, \& G.C.Patton. A mobile phone application for the assessment and management of youth mental health problems in primary care: a randomised controlled trial. BMC family practice, 12(1), 2011. pp.1-14.

[61] J.N. Stinson, C. Lalloo, L. Harris, L. Isaac, F. Campbell, S. Brown, ... \& A. Karim. iCanCope with Pain ${ }^{\mathrm{TM}}$ : User-centred design of a web-and mobile-based self-management program for youth with chronic pain based on identified health care needs. Pain Research and Management, 19(5), 2014. pp.257-265.

[62] Y.X. Chen, Y.P. Hung \& H.C. Chen. Mobile application-Assisted cognitive behavioral therapy for insomnia in an older adult. Telemedicine and e-Health, 22(4), 2016. pp.332-334.

[63] J. Huh, C.J. Cerrada, E. Dzubur, G.F. Dunton, D. Spruijt-Metz, \& A.M. Leventhal. Effect of a mobile just-in-time implementation intention intervention on momentary smoking lapses in smoking cessation attempts among Asian American young adults. Translational behavioral medicine, 11(1), 2021. 216-225.
[64] N. Bidargaddi, G. Schrader, P. Klasnja, J. Licinio, S. \& Murphy. Designing $\mathrm{m}$-Health interventions for precision mental health support. Translational psychiatry, 10(1), 2020. pp.1-8.

[65] R. Whittaker, S. Merry, E. Dorey \& R. Maddison. A development and evaluation process for mHealth interventions: examples from New Zealand. Journal of health communication, 17(sup1), 2012. pp.11-21.

[66] T.A. Dennis \& L. J. O'Toole. Mental health on the go: Effects of a gamified attention-bias modification mobile application in trait-anxious adults. Clinical Psychological Science, 2(5), 2014. pp.576-590.

[67] H. Lee, R. Ghebre, C. Le, Y.J. Jang, M. Sharratt, \& D. Yee. Mobile phone multilevel and multimedia messaging intervention for breast cancer screening: pilot randomized controlled trial. JMIR mHealth and uHealth, 5(11), 2017. e154.

[68] M. Dugas, K. Crowley, G.G. Gao, T. Xu, R. Agarwal, A.W. Kruglanski, $\&$ N. Steinle,. Individual differences in regulatory mode moderate the effectiveness of a pilot mHealth trial for diabetes management among older veterans. PloS one, 13(3), 2018. e0192807.

[69] J.K Carroll, J.N. Tobin, A. Luque, S. Farah, M. Sanders, A. Cassells, ... \& K. Fiscella. "Get ready and empowered about treatment"(GREAT) study: a pragmatic randomized controlled trial of activation in persons living with HIV. Journal of general internal medicine, 34(9), 2019. pp.1782-1789.

[70] P. Mc Kenna, G. Babughirana, M. Amponsah, S.G. Egoeh, E. Banura, R. Kanwagi, \& B. Gray. Mobile training and support (MOTS) serviceusing technology to increase Ebola preparedness of remotely-located community health workers (CHWs) in Sierra Leone. Mhealth, 5. 2019.

[71] D. Ben-Zeev, C.J. Brenner, M. Begale, J. Duffecy, D.C. Mohr \& K.T. Mueser. Feasibility, acceptability, and preliminary efficacy of a smartphone intervention for schizophrenia. Schizophrenia bulletin, 40(6), 2014. pp.1244-1253.

[72] G. T. Ahsan, I.D Addo, S.I. Ahamed, D. Petereit, S. Kanekar, L. Burhansstipanov, L.U \& Krebs. Toward an mHealth intervention for smoking cessation. In 2013 IEEE 37th Annual Computer Software and Applications Conference Workshops 2013. pp. 345-350. IEEE.

[73] L.A. Gilmore, M.C. Klempel, C.K. Martin, C.A. Myers, J.H. Burton, E. F. Sutton, \& L.M. Redman. Personalized mobile health intervention for health and weight loss in postpartum women receiving women, infants, and children benefit: a randomized controlled pilot study. Journal of Women's Health, 26(7), 2017. pp.719-727.

[74] U. Müssener, M. Löf, P. Bendtsen, \& M. Bendtsen. Using mobile devices to deliver lifestyle interventions targeting at-risk high school students: protocol for a participatory design study. JMIR research protocols, 9(1), 2020. e14588.

[75] J. Farao, B. Malila, N. Conrad, T. Mutsvangwa, M.X. Rangaka, \& T.S.Douglas). A user-centred design framework for mHealth. PloS one, 15(8), 2020. e0237910.

[76] A.E. Kazdin, \& S.M. Rabbitt. Novel models for delivering mental health services and reducing the burdens of mental illness. Clinical Psychological Science, 1(2), 2013. pp.170-191.

[77] D. R. Nyatuka, \& R. de la Harpe. Evaluating mHealth Interventions in an Underserved Context Using Service Design Strategy: A Case of Kenya. In Proceedings of the third International Conference on Medical and Health Informatics 2019. pp. 153-160.

[78] S.P. Jones, V. Patel, S. Saxena, N. Radcliffe, S. Ali Al-Marri, \& A. Darzi. How Google's 'ten things we know to be true'could guide the development of mental health mobile apps. Health Affairs, 33(9), 2014. pp. 1603-1611.

[79] R. Schnall, M. Rojas, J. Travers, W Brown III, \& S. Bakken. Use of design science for informing the development of a mobile app for persons living with HIV. In AMIA Annual Symposium Proceedings 2014, p. 1037. American Medical Informatics Association.

[80] H. D. Nguyen, D.C.C Poo, H. Zhang, \& W. Wang. Analysis and design of an mHealth intervention for community-based health education: an empirical evidence of coronary heart disease prevention program among working adults. In International Conference on Design Science Research in Information System and Technology 2017.pp. 57-72. Springer, Cham.

[81] V. P. Cornet, T. Toscos, D. Bolchini, R.R Ghahari, R. Ahmed, C. Daley, ... \& R.J Holden . Untold stories in user-centered design of mobile health: Practical challenges and strategies learned from the design and 
evaluation of an app for older adults with heart failure. JMIR mHealth and uHealth, 8(7), 2020.e17703.

[82] A.M. Polhemus, J. Novák, J. Ferrao, S. Simblett, M. Radaelli, P. Locatelli, ... \& M. Hotopf. Human-centered design strategies for device selection in mhealth programs: development of a novel framework and case study. JMIR mHealth and uHealth, 8(5), 2020. e16043.

[83] E. B. N. Sanders. From user-centered to participatory design approaches. In Design and the social sciences 2002. pp. 18-25. CRC Press.

[84] J. Ross, F. Stevenson, R. Lau, and E. Murray. Factors that influence the implementation of e-health: a systematic review of systematic reviews (an update). Implementation science, 11(1), 2016. p.146.

[85] P. Vink, A.S. Imada, \& K.J. Zink. Defining stakeholder involvement in participatory design processes. Applied ergonomics, 39(4), 2008. p.519526.

[86] ISO. Ergonomics of Human-system Interaction: Part 210: Humancentred Design for Interactive Systems. 2010. ISO.

[87] ISO Human-centred design processes for interactive systems. Geneva: 1999.ISO.

[88] Y.J. Korpershoek, S. Hermsen, L. Schoonhoven, M.J. Schuurmans, \& J.C. Trappenburg. User-centered design of a mobile health intervention to enhance exacerbation-related self-management in patients with chronic obstructive pulmonary disease (copilot): mixed methods study. Journal of medical Internet research, 22(6), 2020. e15449.
[89] A. Good \& O. Omisade. Linking Activity Theory with User Centred Design: A Human Computer Interaction Framework for the Design and Evaluation of. Applied Interdisciplinary Theory in Health Informatics: A Knowledge Base for Practitioners, 2019. p263, 49.

[90] K. Tschimmel. Design Thinking as an effective Toolkit for Innovation. In ISPIM Conference Proceedings 2012. p. 1. The International Society for Professional Innovation Management (ISPIM).

[91] E.G. Carayannis, L. Dezi, G. Gregori, \& E. Calo . Smart environments and techno-centric and human-centric innovations for Industry and Society 5.0: A Quintuple Helix Innovation System view towards smart, sustainable, and inclusive solutions. Journal of the Knowledge Economy, 2021. pp.1-30.

[92] P. Micheli, S. J. Wilner, S. H. Bhatti, M. Mura, \& M.B. Beverland. Doing design thinking: Conceptual review, synthesis, and research agenda. Journal of Product Innovation Management, 36(2), 2019. pp.124-148.

[93] S.T. Shen, M. Woolley \& S. Prior. Towards culture-centred design. Interacting with computers, 18(4), 2006. pp.820-852.

[94] L. Opipari-Arrigan, D.M. Dykes, S.A. Saeed, S. Thakkar, L. Burns, B.A. Chini, ... \& H.C. Kaplan. Technology-Enabled Health Care Collaboration in Pediatric Chronic Illness: Pre-Post Interventional Study for Feasibility, Acceptability, and Clinical Impact of an Electronic Health Record-Linked Platform for Patient-Clinician Partnership. JMIR mHealth and uHealth, 8(11), 2020. e11968. 